\title{
An Endogenous Formation Model of Regional Economic Network and Regional Coordinated Development in China
}

\author{
Zhengxia Tang \\ School of Economics \\ Central University of Finance and Economics \\ Beijing, China \\ Fengrong Liu \\ Center for China Fiscal Development \\ Central University of Finance and Economics \\ Beijing, China \\ Lapo Hou \\ Institute of Yi Language and Culture \\ Xichang University, Xichang \\ China
}

\begin{abstract}
Regional coordinated development is a rational choice out of interactions over the spatial economic networks. This paper proposes 3 types of effective regional economic networks due to endogenous development choice, which based on a simplification of the complicated real economy world and utility maximization process. The government will intervene in the endogenous development of the region if coordinated development of the region is conducive to the overall interests. It further implies that the ultimate goal is to establish a completely connected regional economic network or regionally economic integration pattern.
\end{abstract}

Keyword: regional coordinated development, regional economic network, endogenous mechanism

\section{Introduction}

Enlarging gaps among China's regional development have imposed negative impact on its economy. Meanwhile, divisions and specializations of labor and market between regions tend to be a powerful growth engine, especially when confronted with domestic and global economic fall. In China, only a few of the provinces from the eastern coastline region are developing coordinately, whereas their counterparts in West China achieve poor balance (Zhang, 2013). National strategies, such as the Western Development Drive, Northeast China Revitalization Program, Central Region Rising Strategy and programs to encourage the leading role of East China, are put up and implemented accordingly (Liu, 2014). However, not only discordant development remains rarely changed in the last decade, but also new gaps emerge because of spatial aggregation, geographic comparison and initial endowments (Zhou, 2016). New strategies to coordinate regional economic development, including The Yangtze River Economic Belt strategy and Belt and Road strategy, show government's increasing efforts to regional balance and gap shrinkage (Yang, 2016).

Researchers also show increasing interests in regional development coordination problems, clarifying the concept, analyzing reasons and offering solutions. Some holds that regional development coordination means deeper economics connection, sustainable economic development and narrowing disparity between regions (Wang, 2001; Qin, 2011). A primary consensus exists that the reason to pursue coordinated regional development is to narrow gaps and improve overall welfare. A large proportion of studies discuss the mechanism and solutions. Lin (1998) and Fan (2006) calls for a unified market system in this country. Li (2000) emphasizes the role of national strategy, attributing inter-regional disparities to unfair strategies after the economic reform in 1987. It is necessary to carry out national strategies for a coordinated development across the country (Liu, 2014). Fan (2010) finds that industrial agglomeration in East China doesn't lead to enlarging income gaps between regions and believes industrial agglomeration is compatible with regional economic coordination. 
Besides, researchers have introduced complex network theory and method into regional economics, which establishes a new field called regional economic network to analyze regional economy phenomenon and canons of economics (Sang, Qin, 2014). According to the theory, two or more regions voluntarily working together is called a network while different networks together can form network structure (Ma, 2014). Networks can appear inside economic areas like Pearl River Delta Economic Zone or Yangtze River Delta Economic Zone, and also lie between regions. Under these circumstances, related regions can be treated as one integrated entity and coordinated development is thus an endogenous demand (Miller, 2002; Peng, 2007). Collaboration and networks between regions is considered as the outcome of rational decisions driven by their own desires (Feiock, 2007). Network analysis method is an applicable way to tackle cross-regional problems (Kahler, Lake, 2009). Liu (2014) acclaims that complex network analyzing method contributes to shed light on the overall development situation when applied to city network studies.

Above all, we consider regional economic network as a regional phenomenon and interregional coordinated development the result of endogenous choice. Network theory is a renewed framework to do regional economy research. Through network theory we hereby try to answer how to comprehend mechanism of endogenous choice and design government intervention in regional economic development coordination.

\section{An Endogenous Formation Model of Regional economic network}

\subsection{Regional Economic Network}

Frequent economic interactions between regions, e.g. exchange of production factors, industrial chains and logistics can be analyzed under network theory when we consider the concept those regions as a complex network. Regional economic network is the structure that relationships and interactions between regions (Aoyama, 2011).

According to the definition, suppose a regional economic system consists of limited regions who contact and correlate with each other to form a network. Each certain region is a spot in this network. Apparently, a regional system (network) is a point set $R, R=\{1,2,3, \cdots n\}, n \in N$. Economic connection or relationship between two regions is called Edge, $E=\left\{E_{12}, E_{23} \cdots E_{i j} \cdots\right\}$. We define edges with no specific direction though they may represent a relationship that has certain direction in the real world. A regional economic network is therefore marked as $N=\{R, E\}$. When all the regions are independent of each other, an empty network exists; when regions have connections to all the others, it is called a completely connected network. The network we established above can be interpreted by complex network theory.

\subsection{Endogenous Formation Mechanism of Regional Economic Network}

After defining the concept of regional economic network, we will discuss how this network comes into being. Jackson (1996) reckons that economic network is the result of the participants' economic activities. Therefore, economic network is endogenously constructed (Guo, 2006). We hereby take regions as rational decision makers while regional economic network as the result of the decisions.

We assume that:

a. Any arbitrary region i can generate utility $\left(u_{i}\right)$ when it is economically connected to surrounding regions. Effect coefficient between Region $i$ and Region $\mathrm{j}$ is $\mathrm{a}_{\mathrm{ij}}$.

b. Distance decay coefficient $\sigma_{\mathrm{ij}}, \sigma \epsilon(0,1)$ illustrates the impact of distance in economic networks on utility. A direct utility and indirect utility differ whether there are intermediary regions in the economic connection.

c. Costs $\left(\mathrm{c}_{\mathrm{ij}}\right)$ are generated and paid in interregional economic activities. We only take direct interactions into accounts to simplify this question.

d. We assume $\mathrm{a}_{\mathrm{ij}}=\mathrm{a}_{\mathrm{ji}}, \mathrm{c}_{\mathrm{ij}}=\mathrm{c}_{\mathrm{ji}}, \sigma_{\mathrm{ij}}=\sigma_{\mathrm{ji}}$ in this model although they are not necessarily equal in reality.

An endogenous model of Regional economic network is formulated as follows. A connection will tend to be built if positive utility is generated in interregional economic activities and vice versa.

$$
U_{i}=\sum_{i, j \in N} a_{i j} \sigma_{i j} d_{i j}-\sum_{i, j \in N} c_{i j} \cdot
$$

\subsection{Effectiveness of Regional Economic Network}


Suppose a regional system containing $\mathrm{n}$ regions with $\mathrm{k}$ connections, $\mathrm{k} \geq \mathrm{n}-1$. The network utility can be decomposed of two parts: $2 \mathrm{k} \sigma$ from direct connections and $2\left(\frac{\mathrm{n}(\mathrm{n}-1)}{2}-\mathrm{k}\right) \sigma^{2}$ from indirect connections. The network costs are $2 \mathrm{kc}$. Based on (1), overall utility of a regional economic network is:

$$
\begin{array}{r}
\mathrm{U}_{\mathrm{k}}=2 \mathrm{k} \sigma+2\left(\frac{\mathrm{n}(\mathrm{n}-1)}{2} \mathrm{k}\right) \sigma^{2}-2 \mathrm{kc} \cdots \cdots \\
\mathrm{U}_{\mathrm{g}} \leq \mathrm{U}_{\mathrm{k}}, \mathrm{g} \in\{\mathrm{g} \mid \mathrm{g} \leq \mathrm{k}\}
\end{array}
$$

a. When $\mathrm{k}=\mathrm{n}-1$,

$$
\mathrm{U}_{\mathrm{n}-1}=2(\mathrm{n}-1)\left(\sigma+\left(\frac{\mathrm{n}-2}{2}\right) \sigma^{2}-\mathrm{c}\right)
$$

A star connection is then constructed. Furthermore, when $\sigma+\left(\frac{n-2}{2}\right) \sigma^{2}<c, B_{n-1}<0$. It means that an empty network where no connection exists is the only effective type of networks.

b. When it turns to networks where connections exit, we get

$$
\mathrm{U}_{\mathrm{k}+1}-\mathrm{U}_{\mathrm{k}}=2 \sigma-2 \sigma^{2}-2 \mathrm{c}, \forall \mathrm{k} \geq \mathrm{n}-1
$$

Equation (4) shows that the network utility is independent of the quantity of edges. The edge amount will not exceed n-1 if $\sigma-\sigma^{2}<c$. When we decrease one edge from the star-type network, the total utility of the network will drop2(c $\left.-\sigma+\left(\frac{\mathrm{n}-2}{2}\right) \sigma^{2}\right)$. As a result, the network will remain stable or add its edges. Taking (4) into consideration, when $\sigma-\sigma^{2}<c$,total utility will decrease by $2 \sigma-2 \sigma^{2}-2 c$ if we add an additional edge to the network. As a result, the network will remain stable or cut down its edges. In conclusion, when $\sigma+\left(\frac{\mathrm{n}-2}{2}\right) \sigma^{2}>$ $c>\sigma-\sigma^{2}$,the star-type network is the only effective one.

c. Continuing discussing about a non-empty network but $\sigma-\sigma^{2}>c$

According to (4), one more edge will add at least the utility of $2 \sigma-2 \sigma^{2}-2 c$, which is positive. In this situation, an increase in the edge of regional economic network will last until the formation of a completely connected network.

\subsection{An Regional Economic Network Model}

This paper builds an idealized regional economic network model based on Central Place Theory and CorePeriphery Model. These two foundations are of vital importance in our work because they help to expound both locations and regional relationships. Suppose there are 7 regions composing a regional economic network with one of them on the central point and others on the periphery. Utility of each type of network can be calculated through regional utility function, $\mathrm{U}_{\mathrm{i}}=\sum \mathrm{a}_{\mathrm{ij}} \sigma_{\mathrm{ij}} \mathrm{d}_{\mathrm{ij}}-\sum \mathrm{c}_{\mathrm{ij}}$.

a. Star Connection(Figure 1)

In a Star connection regional economic network with 7 regions(Figure 1), the central point is 1 and other points are marked point 2 to $7 . \mathrm{We}$ seta $_{\mathrm{ij}}=\mathrm{a}_{\mathrm{ji}}, \mathrm{c}_{\mathrm{ij}}=\mathrm{c}_{\mathrm{ji}}, \sigma_{\mathrm{ij}}=\sigma_{\mathrm{ji}}$.Utility of the star connection network is $\mathrm{u}_{\mathrm{n}}\left(\mathrm{g}^{*}\right)$.

$$
\begin{gathered}
\mathrm{u}_{1}\left(\mathrm{~g}^{*}\right)=6 \sigma-6 \mathrm{c} \\
\mathrm{u}_{2}\left(\mathrm{~g}^{*}\right)=\mathrm{u}_{3}\left(\mathrm{~g}^{*}\right)=\cdots=\mathrm{u}_{7}\left(\mathrm{~g}^{*}\right)=\sigma+5 \sigma^{2}-\mathrm{c} \\
\mathrm{U}\left(\mathrm{g}^{*}\right)=\sum_{\mathrm{n}=1}^{7} \mathrm{u}_{\mathrm{n}}\left(\mathrm{g}^{*}\right)=12 \sigma+30 \sigma^{2}-12 \mathrm{c} \cdots \cdots(5)
\end{gathered}
$$

b. Star Connection plus one Edge(Figure 2)

We randomly add one more edge to star connection, for edge from point 2 to point 6 . The current utility of the network is

$$
\begin{gathered}
u_{1}\left(g^{\prime}\right)=6 \sigma-6 c \\
u_{2}\left(g^{\prime}\right)=u_{6}\left(g^{\prime}\right)=2 \sigma+4 \sigma^{2}-c \\
u_{3}\left(g^{\prime}\right)=u_{4}\left(g^{\prime}\right)=u_{5}\left(g^{\prime}\right)=u_{7}\left(g^{\prime}\right)=2 \sigma+4 \sigma^{2}-c \\
U\left(g^{\prime}\right)=\sum_{n=1}^{7} u_{n}\left(g^{\prime}\right)=14 \sigma+28 \sigma^{2}-14 c \cdots \cdots
\end{gathered}
$$

c. Complete Connection(Figure 3)

The utility of a complete connection network is $u_{n}\left(g^{v}\right)$.

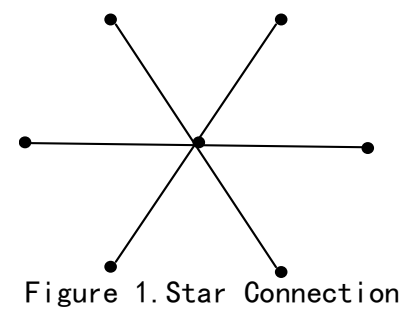

example, an

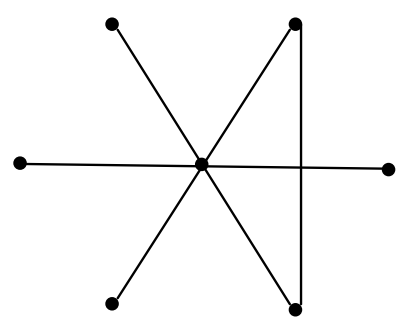

Figure 2. Plus One Edge 


$$
\begin{array}{r}
\mathrm{u}_{1}\left(\mathrm{~g}^{\mathrm{v}}\right)=6 \sigma-6 \mathrm{c} \\
\mathrm{u}_{2}\left(\mathrm{~g}^{\mathrm{v}}\right)=\mathrm{u}_{3}\left(\mathrm{~g}^{\mathrm{v}}\right)=\cdots=\mathrm{u}_{7}\left(\mathrm{~g}^{\mathrm{v}}\right)=3 \sigma+3 \sigma^{2}-3 \mathrm{c} \\
\mathrm{U}\left(\mathrm{g}^{\mathrm{v}}\right)=\sum_{\mathrm{n}=1}^{7} \mathrm{u}_{\mathrm{n}}\left(\mathrm{g}^{*}\right)=24 \sigma+18 \sigma^{2}-24 \mathrm{c} \cdots \cdots(7)
\end{array}
$$

When $\mathrm{c}>\sigma-\sigma^{2}, \mathrm{U}\left(\mathrm{g}^{*}\right)>U\left(\mathrm{~g}^{\mathrm{v}}\right)>U\left(\mathrm{~g}^{\mathrm{v}}\right)$ so that Star connection network is the only effective regional economic network. When $c<\sigma-\sigma^{2}$, we get $\mathrm{U}\left(\mathrm{g}^{*}\right)<U\left(\mathrm{~g}^{\mathrm{c}}\right)<U\left(\mathrm{~g}^{\mathrm{v}}\right)$ which means complete connection network is the

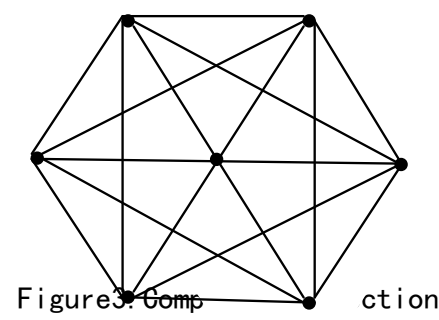
only effective regional economic network. Both the two connection types indicate that a region could lower its costs and gain more profits if it works with its neighbor regions.

\section{Effectiveness of Regional Economic Network under Government Intervention}

Now that we have got preliminary evidence that regional economic network formed endogenously and can run automatically effective, do we still need government intervention? An (2007) specifies that market mechanism merely enlarges cross-regional income gaps when it comes to a given stable situation. Government must take measures to protect markets and coordinate regional development, especially giving special policies to less developed areas to ensure their proportion in the market. We make adjustment to the endogenous model and define government efforts as coordinating regional development and lowering network costs. The costs is constitutive of three sources: first, basic costs of economic activities; second, costs produced by geographic features, for instance, network costs of East China (more flatland) is less than Middle-West China (more mountains and plateau); third, political costs owing to administration division, regional protectionism, household registration limits, etc.

Supposing $\mathrm{c}_{\mathrm{ij}}=\mathrm{c}_{\mathrm{ij}}^{1}+\mathrm{c}_{\mathrm{ij}}^{2}+\mathrm{c}_{\mathrm{ij}}^{3}$,and $\mathrm{c}_{\mathrm{ij}} \gg \mathrm{c}_{\mathrm{ij}}^{1}$, calculations in formula (3)and(4)gives

$$
\begin{gathered}
U_{n-1}=2(n-1)\left(\sigma+\left(\frac{n-2}{2}\right) \sigma^{2}-\left(c^{1}+c^{2}+c^{3}\right)\right) \\
U_{k+1}-U_{k}=2 \sigma-2 \sigma^{2}-2\left(c^{1}+c^{2}+c^{3}\right), \forall k \geq n-1
\end{gathered}
$$

The effectiveness of the network is:

a. When $\sigma+\left(\frac{n-2}{2}\right) \sigma^{2}<\left(c^{1}+c^{2}+c^{3}\right)$,empty network is the only effective one;

b. When $\sigma-\sigma^{2}<\left(c^{1}+c^{2}+c^{3}\right)<\sigma+\left(\frac{n-2}{2}\right) \sigma^{2}$,star connection network is the only type that is effective;

c. When $\sigma-\sigma^{2}>\left(c^{1}+c^{2}+c^{3}\right)$, complete connection network is the only effective network.

When $c^{2}$ and $c^{3}$ can be controlled by the government and $c_{i j} \gg c_{i j}^{1}$, government will seek to decrease costs to guarantee that $c^{2}+c^{3}$ approaches zero. Most probably, the goal of the government is to make sure $\sigma-\sigma^{2}>$ $\left(c^{1}+c^{2}+c^{3}\right)$. At that time, complete connection network is the only effective one. In a word, government can play an important role in coordinating regional development although it is not easy.

\section{An Explanation of Balanced Development in China's Regional Economy}

\subsection{The Approximately Complete Connection Urban Agglomeration in the East of China}

Regions in East China cover a large stretch of plain lands. The advantageous location and dense transportation lines contribute to better development opportunities since 1978. The regions develop relatively coordinated and gaps are not so large between them. It can be explained by regional economic network method that connections between eastern regions effectively cut the costs down and gain much benefits. A tendency to complete connection seems to be the status quo in East China. 
Take urban agglomeration in Yangtze River Delta- a typical one in East China- for example, is currently the most open, most active and most coordinated areas in China. Daily frequency of both high-speed railway and ordinary railway betweenits 16 cities, asdisplayed by Figure 4 and Figure 5, is very high. Transportation can be an ideal indicator of economic connections according to its initial design and also a natural signal of visible linkage of different regions. Figure 4 shows that there are frequent high-speed railway runs between all cities except Nantong, Taizhou, Yangzhou and Zhoushan. Ordinary railway lines further describe an almost complete connection type in these areas in Figure 5.

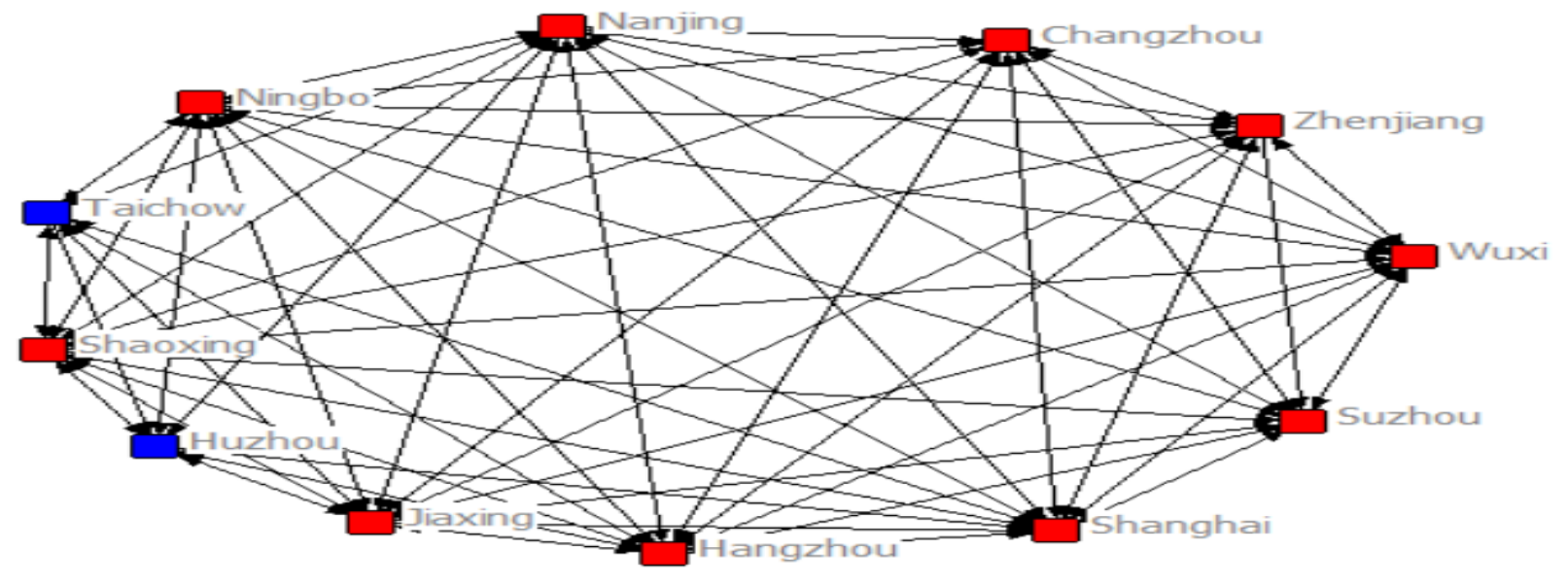

Figure 4.Daily Frequency of High-speed Railway between 16 Cities of Yangtze River Delta(2014) ${ }^{1}$

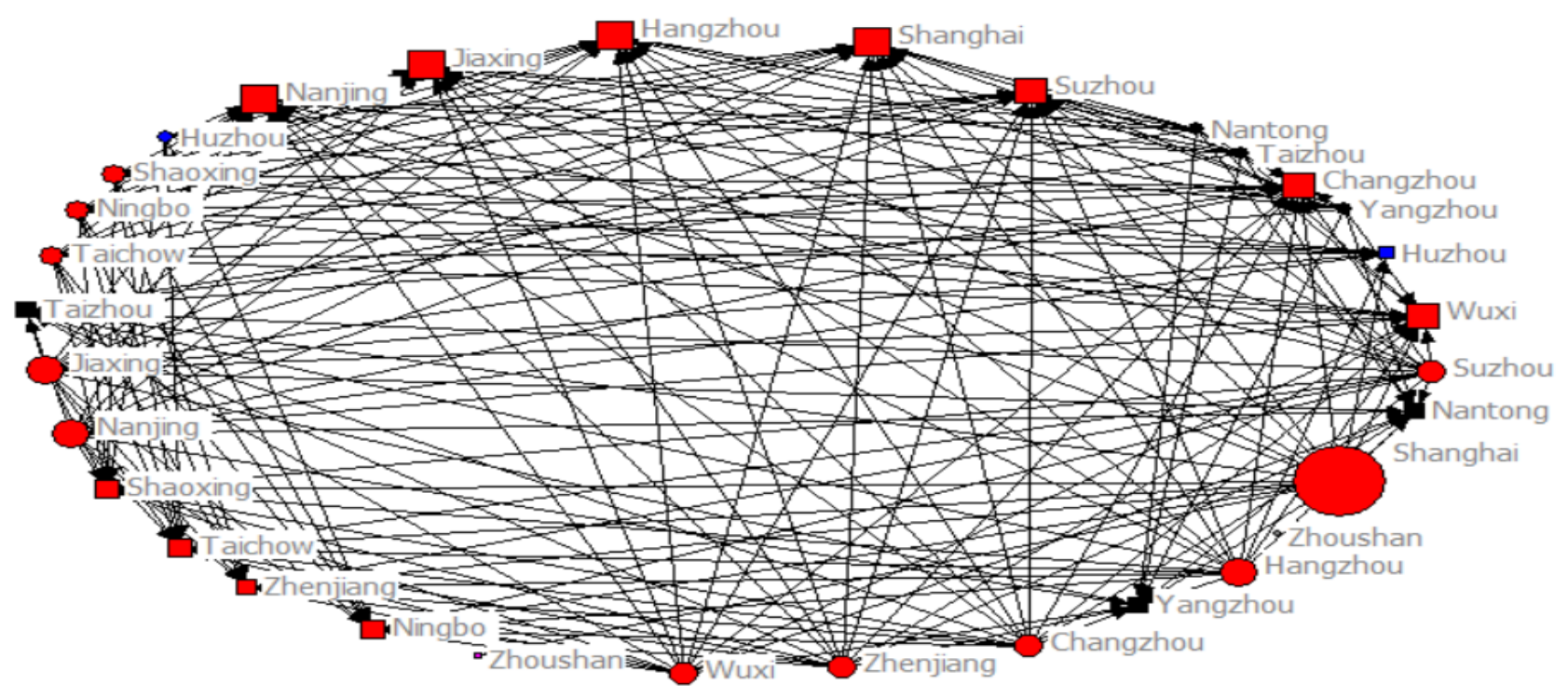

Figure 5. Daily Frequency of Ordinary Railway between 16 Cities of Yangtze River Delta (2014) ${ }^{2}$

High-speed railway and ordinary railway networks is one of the reflections of economic correlations, other networks like internet, financial networks, industrial networks and logistics are more complicated structures. Regional economic network is a summation of them all and is likely to display more connections between regions.

4.2.The Star-type Connected Urban of Agglomeration in the Middle and West of China

Meanwhile, urban agglomeration is a rare phenomenon in Middle and West China. Gaps of development level are not as that small in East China. Sichuan Province in West China is a one of the most powerful one.

${ }^{1}$ Data source: $\mathrm{Mu}$ chenglin,Lu lin, et al. Research on Yangtze River Delta Tourist Traffic Pattern and Linkage Under the

High-Speed Railway Network[J]. Economic Geography2015,12.

${ }^{2}$ Same as Footnote 1. 
The spatial economic network of cities in Sichuan (Figure 6) is merely a star connection type. Capital city like Chengdu, can be seen as the core of this network who has strong connections to all the other cities while there are not enough linkage between the periphery cities. It is an essential Core-Periphery pattern with a center point city Chengdu.

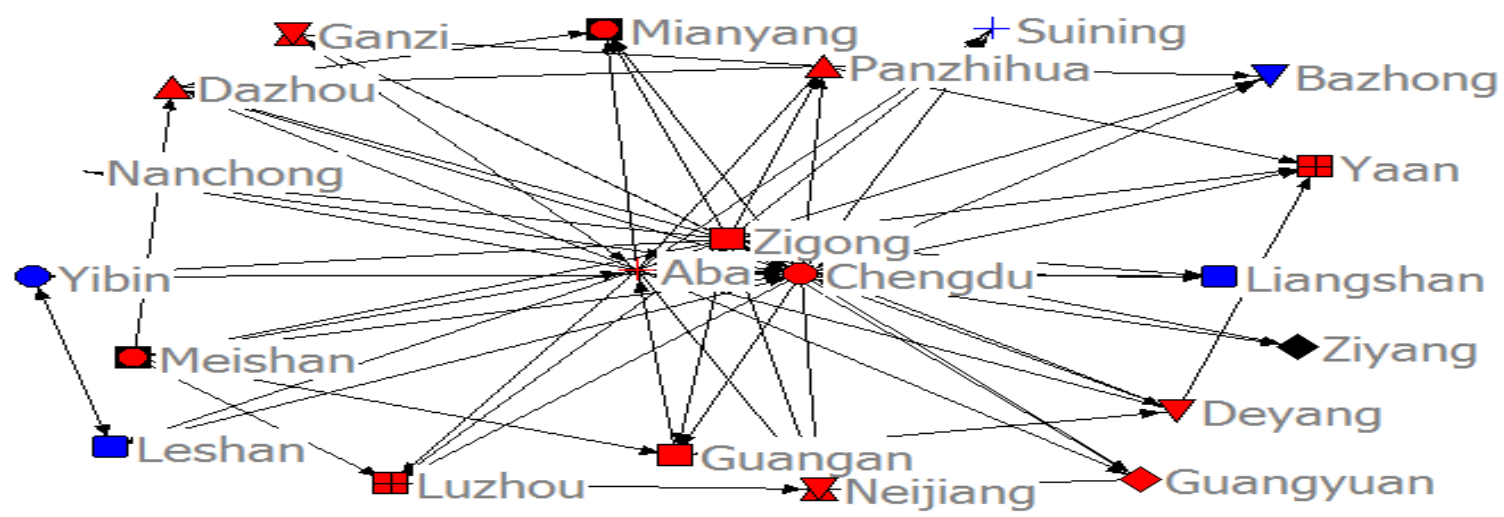

Figure 6.Star Connection Network of 21 Cities in Sichuan Province ${ }^{3}$

\subsection{The Agglomeration of Extremely Poor areas and Their Closed Development}

Agglomeration of extremely poor areas in China is mostly featured with ethnic inhabitants, remote and territory locations. Bad climate, frequent natural calamities and inadequate infrastructure deteriorate their development. These areas are comparatively closed leading to more connection costs. Table 7 exhibits fix assets investment of some infrastructure from 2011 to 2013. Despite the increasing and promising development of roads to meet preliminary demand, other constructions like railway and inland river investment are still limited and in the early stage.

Table 1.Fixed Assets Investment of Transportation in the Aggregated Extremely Poor Areas ${ }^{4}$ (billion YUAN)

\begin{tabular}{lllcc}
\hline Areas & Total & Roads construction & $\begin{array}{c}\text { Inland river } \\
\text { construction }\end{array}$ & $\begin{array}{c}\text { Other } \\
\text { constructions }\end{array}$ \\
Liupan mountain areas & 242080.8 & 240833.5 & 969.2 & 278.1 \\
Qinba mountain areas & 557481.0 & 554741.6 & 2739.4 & \\
Wuling mountain areas & 619727.7 & 613217.9 & 6509.8 & \\
$\quad$ WUmeng mountain areas & 390099.4 & 390099.4 & & \\
$\quad$ Dianguiqian stony desertification & 482420.4 & 476643.8 & 5737.8 & 38.8 \\
areas & 204478.4 & 202638.3 & 871.5 & 968.6 \\
$\quad$ Dianxi mountain areas & 33989.3 & 33989.3 & & \\
$\quad$ Daxinganling south mountain areas & 245610.7 & 245610.7 & & \\
$\quad$ Yan-taihang mountain areas & 113120.7 & 113104.4 & 16.3 & \\
$\quad$ Lvliang mountain areas & 177015.6 & 174462.0 & 2487.0 & 66.6 \\
$\quad$ Dabie mountain areas & 139848.1 & 139803.1 & & 45.0 \\
$\quad$ Luoxiao mountain areas & 3205870.2 & 3185142.1 & 19331.0 & 1397.1 \\
$\quad$ Total &
\end{tabular}

In other words, the extremely poor areas in China would generate high costs if they set out to coordinate, although the costs would also bring them benefits or utility. Closed development is an endogenous choice out of all the facts above. However, gaps will continue enlarging if letting it go. Government intervention is a must to encourage coordination and cut down costs. Measures such as district arrangement or planning can promote cooperation and resources exchange between these poor areas (Dai, 2008).

\footnotetext{
${ }^{3}$ Data source: Sichuan Province Statistics Yearbook 2013.

${ }^{4}$ Data source: China Transportation Statisitcs Yearbook 2013.
} 


\section{Discussion}

Regional economic network is an endogenously formed process and a result of rational choice. When costs are too high for connections between regions, they will choose a close development method or form empty network according to the analysis in this paper. The second network type is star connection which is common in reality. This type suits the regions facing not extreme costs. As long as the utility gained is more than costs in a star-type network, regions tend to coordinate with others and finally will form a complete connection network. Considering the reality in China, government intervention is necessary to bridge the gaps between regions and encourage coordinated development.

Further revise can be done on this paper. First, we propose several hypotheses to describe an idealized regional economic network, which may not fit the reality. For example, we set the effect coefficients between two regions are mutually equal as well as the distance decay coefficients, which is not the fact. More developed regions are more attractive to labor and other resources, causing resources to flow to these areas. Although labor migrating to more developed regions contributes to the coordination, an fundamental prerequisite must be met. The prerequisite is that the labor resources in less developed regions must be homogenous and indistinctive so that the migration will not worsen its current quality of labor market. Apparently, labor resource varies and high-quality ones migrate even more in the real world. The migration may harm the development of less developed regions, resulting in poverty development trap and even vicious circle. Besides, regional economic network can produce negative effects, which has not been discussed in this paper.

\section{References}

An Husen.Industry Spatial Distribution, Income gap and Government Intervention [J]. Social Sciences in Guangdong.2007,4. Aoyama Y, Murphy J T, Hanson S. Key Concepts in Economic Geography [M]. Los Angeles: Sage Publication Ltd, 2011:181-187.

Dai Hongwei.From Disequilibrium to Equilibrium: Regional Economic Development Strategy Change since 1978 [J]. Journal for Party and Administrative Cadres.2008,1.3-6.

Dai Hongwei.Regional Economy Coordination and County Economy Development [N].Daily Economic Newspaper in Hebei.2006,6.

Fan Jianyong,Xie Qiangqiang.Economic Development Pattern Change Impact on China's Carbon Industry [J]. Economic Research Journal.2010,4.

Feiock, R ichard C.Rational Choice and Regional Governance [J].Journal of Urban Affairs,2007,29 ( 1 ) : 47-63.

Guo Lei,Xu Xiaoming.Complex Network [M].Shanghai Education Press.2006,11.235-247.

Jiang Haiqing.Several Theoretical Questions on Regional Economy Coordinated Development [J] Research on Financial and Economic Issues.1995,6.

Kahler M,Lake D A. Economic Integration and Global Governance: Why so Little Supranationalism? [M].The Politics of Global Regulation. Princeton University Press,Princeton,2009 : 242-277.

Liu Beilin,Suhui,Zhangwentian.Regional Coordinated Development Analysis Based on Complex Network [J]. Journal of Commercial Economics.2014,22.

Liu Yin.The Institution Research of Regional Economic Coordinated Development about China [D].Jilin University.2014,12.

Ma Jie,Suo Liming,Chen Bin. From Collaborative Zone to Collaborative Network: Structure, Pathway and EvolutionThe Analysis 191 Intergovernment Agreements in "9+2" Zone [J]. China Soft Science.2014,12.

Miller,David Y.The Regional Governing of Metropolitan America[M].Boulder,Colorado: Westview Press,2002.

Peng rongsheng.On the Meaning, Mechanism and Evolution of Coordinative Development of interregional Economy [D].Henan University. 2007,4.54-58.

Sang Manlin,Tan Chenglin. A New Trend In Regional Economics: Research On Regional Economic Networks [J]. Human Geography.2014,3.28-35.

Tan Chenglin,Zhang hua,Mao chao.Regional Economy Coordinated Development: Concept, Standard and Evaluation [J]. Reform of Economic System.2011(4).

Wang wenjin.Research on China's Regional Coordinated Development [D].Party School of the Central Committee of C.P.C,2001,6.

Wei houkai.Regional Economic Theory and Policy [M].China Social Science Press.2016.

Yang Kaizhong.Basic Features of Regional Coordinated Development [J]. China National Conditions and Strength.2016,5.6-10.

Zhang Weili,Li Jianxin.Analyzing Spatial Pattern and Evolution about Administrative Economic Coordinated Development Degree of China [J]. Economic Geography.2013,6.8-15.

Zhou Wen,Zhao Guoqing.Regional Economy Coordinated Development: Spatial Agglomeration and Impacts-based on 2136 Counties 1999 and 2010 [J]. Economic Science.2016, 4. 